\title{
Studies on Phenolic Steroids in Human Subjects. VII. Metabolic Fate of Estriol and Its Glucuronide*
}

\author{
Avery A. Sandberg $\dagger$ and W. Roy Slaunwhite, Jr. \\ (From the Roswell Park Memorial Institute, Buffalo, N. Y.)
}

Estriol has been considered a metabolic product of the more active estrogens, estrone $(1,2)$ and indirectly estradiol. Recently, an alternative pathway has been proposed (3) based on the observations that $16 \alpha$-hydroxydehydroepiandrosterone is present in high concentrations in cord blood and that it is aromatized by placental enzymes. During pregnancy the placenta has been thought the source of the mother's urinary estriol, but recent evidence indicates that the fetus (4-6) and, in particular, the fetal liver (7) may play an important role in the conversion of the estrone to estriol (8). Although estriol has been considered an end product of estrogen metabolism, its fate and metabolism have received considerable attention because it does have some estrogenic effects, although they are much smaller in some respects and larger in others than those of its precursors, estradiol and estrone (9).

Several interesting studies have appeared on the fate of estriol administered to human subjects. Schiller and Pincus (10) administered estriol triacetate and recovered $57 \%$ of the estriol in the urine, as shown by bioassay of the material in the urine. The metabolism of estriol was reinvestigated by Levitz, Spitzer, and Twombly (11), using $\mathrm{C}^{14}$-labeled steroid. They injected about $5 \mu \mathrm{c}$ of estriol-16- $\mathrm{C}^{14}$ in $7 \mathrm{ml}$ of propylene glycol intramuscularly into two adult women. The recovery of the radioactivity in the urine in 3 days was 58 and $90 \%$, respectively. A most interesting observation was the appearance of "small but significant amounts of radioactive 16-ketoestradiol and 16-epiestriol" in the urine of the subjects. This finding pointed to the presence in the body

\footnotetext{
* Submitted for publication November 6, 1964 ; accepted December 31, 1964.

This study has been supported in part by grants A-1240 and CA-03559 from the National Institutes of Health.

† Send requests for reprints to: Dr. Avery A. Sandberg, Roswell Park Memorial Institute, Buffalo, N. Y. 14203.
}

of enzymes capable of oxidizing the hydroxyl group at position 16, a finding not reported in the past.

The attention of investigators has recently been directed toward steroid conjugates, not only because they are excreted in that form, but owing to the demonstration that steroid sulfates may, in some instances, serve as biosynthetic intermediates (12-14), that dehydroepiandrosterone sulfate is secreted by the adrenal cortex (15), that estrone circulates in the blood as a sulfate (16), and that steroid sulfates appear to be biologically active (17).

In previous studies we have reported on the clearance of $\mathrm{C}^{14}$-labeled estrone and estradiol from the plasma of human subjects and on the significance of the enterohepatic circulation as a metabolic pathway for these steroids (18). The present study extends these observations to $\mathrm{C}^{14}$ estriol and the glucuronide of this estrogen. In this paper are presented data on the distribution of radioactivity in the bile, feces, and urine following the intravenous injection of $\mathrm{C}^{14}$-estriol or $\mathrm{C}^{14}$-estriol glucuronide. The rate of clearance from the blood of the free and conjugated steroids and their metabolites is compared to observations obtained with $\mathrm{C}^{14}$-labeled estrone and estradiol. In addition, the isolation and identification of the metabolites of the injected steroids are described and the results compared with those present in the literature.

\section{Methods}

One to $5 \mu \mathrm{c}$ of $16-\mathrm{C}^{14}$-estriol or $16-\mathrm{C}^{14}$-estriol glucuronide (SA, $22 \mu \mathrm{c}$ per $\mathrm{mg})^{1}$ was injected intravenously. The glucuronide was synthesized in our laboratory by biosynthetic means described previously (19). All the steroids injected were shown to be pure by chromatographic and countercurrent distribution techniques. The noncon-

1 The $\mathrm{C}^{14}$-estriol was synthesized by $\mathrm{Dr}$. Mortimer Levitz from whom it was obtained through the courtesy of the American Cancer Society. 
TABLE I

Excretion of radioactivity in the urine and stools of women injected with $C^{14}$-estriol and the radioactivity extractable following various hydrolytic procedures*

\begin{tabular}{|c|c|c|c|c|c|c|c|c|}
\hline \multirow[b]{2}{*}{ Subject } & \multirow[b]{2}{*}{ Age } & \multirow[b]{2}{*}{$\begin{array}{l}\text { Total } \\
\text { radio- } \\
\text { activity } \\
\text { in urine }\end{array}$} & \multicolumn{4}{|c|}{ Radioactivity in hydrolytic fractions } & \multirow[b]{2}{*}{$\begin{array}{c}\text { Total hydro- } \\
\text { lyzable } \\
\text { radio- } \\
\text { activity }\end{array}$} & \multirow[b]{2}{*}{$\begin{array}{l}\text { Radio- } \\
\text { activity } \\
\text { in stools }\end{array}$} \\
\hline & & & Free & $\begin{array}{l}\beta \text {-Glucu- } \\
\text { ronidase }\end{array}$ & $\begin{array}{c}\text { Weak } \\
\text { acid } \\
\text { (pH 1) } \\
\text { "sulfates" }\end{array}$ & $\begin{array}{l}\text { Strong } \\
\text { acid }\end{array}$ & & \\
\hline $\begin{array}{l}1 \\
2 \\
3 \\
4 \\
5\end{array}$ & $\begin{array}{l}67 \\
69 \\
71 \\
56 \\
43\end{array}$ & $\begin{array}{l}81.1 \\
88.8 \\
82.0 \\
84.8 \\
88.0\end{array}$ & $\begin{array}{l}1.0 \\
2.6 \\
3.4 \\
2.8 \\
0.8\end{array}$ & $\begin{array}{l}49.4 \\
43.0 \\
56.8 \\
54.3 \\
37.9\end{array}$ & $\begin{array}{r}20.6 \\
5.5 \\
9.1 \\
9.2 \\
10.1\end{array}$ & $\begin{array}{r}3.0 \\
10.1 \\
4.5 \\
8.8 \\
2.2\end{array}$ & $\begin{array}{l}74.0 \\
61.2 \\
73.8 \\
74.1 \\
51.0\end{array}$ & $\begin{array}{l}0.8 \\
2.8 \\
1.3 \\
0.0 \\
4.4\end{array}$ \\
\hline
\end{tabular}

* Results are shown as percentages of injected dose excreted in 72 hours.

jugated $\mathrm{C}^{14}$-estriol was dissolved in 1 to $2 \mathrm{ml}$ of absolute alcohol and then diluted with 30 to $50 \mathrm{ml}$ of saline, which was injected intravenously over a period of 1 to $2 \mathrm{~min}$ utes. The $\mathrm{C}^{\mathbf{1 4}}$-estriol glucuronide was easily dissolved in $30 \mathrm{ml}$ of saline and injected similarly. The free $\mathrm{C}^{\mathbf{1 4}}$ estriol was injected into ten female subjects, five with biliary fistulas ( $T$-tube drainage). One pregnant woman was injected in the last trimester. The estriol glucuronide was administered to six women, three of whom had biliary fistulas. All the subjects were in good nutritional state, and none had evident renal or liver disease.

All the patients with $\mathrm{T}$-tube drainage were injected no sooner than the third postoperative day and had no evidence of impaired liver function. In each case the patient's condition had been stabilized without fever or other complications after oral intake of fluids and food had been established. Complete biliary collections were assured by a special apparatus and by the appearance of acholic stools.

The conditions for the collection of bile and urine and the procedures used for the determination of radioactivity, separation of the plasma from the erythrocytes, and hydrolytic methodologies employed have been described in previous publications $(19,20)$.

\section{Results}

Studies with $C^{14}$-estriol. Nearly $85 \%$ of the radioactivity injected was excreted within 72 hours in the urine of subjects given $\mathrm{C}^{\mathbf{1 4}}$-estriol (Table I), with about $30 \%$ being excreted within 4 hours and $50 \%$ within 12 hours. This pattern contrasts with that observed subsequent to the injection of $\mathrm{C}^{14}$-estrone on $\mathrm{C}^{14}$-estradiol; when these two estrogens were injected, the peak excretion of urinary radioactivity often occurred 24 to 72 hours following the injection. In the case of $\mathrm{C}^{14}$-estradiol significant excretion of radioactivity in the urine was present 72 to 120 hours after the administration of the steroid (18). The average excretion of radioactivity in the bile, in a period of 72 hours following the injection of $\mathrm{C}^{14}$ estriol, was approximately $23 \%$ (Table II). Since only $2 \%$ of the radioactivity could be accounted for in the stools of the nonfistula subjects, the findings would indicate that the preponderant part of the biliary radioactivity following $\mathrm{C}^{14}$-estriol administration is reabsorbed in the gastrointestinal tract and excreted in the urine. The fact that the biliary fistula subjects excreted significantly lower amounts of radioactivity in the urine ( $70 \%$ vs. $85 \%$ ) than did the nonfistula women would support this statement. The percentage of radioactivity excreted in the bile following the injection of $\mathrm{C}^{14}$-estriol was much less than that obtained following the injection of $\mathrm{C}^{14}$-estrone or $\mathrm{C}^{14}$-estradiol $(50 \%)$.

Of the $85 \%$ of injected radioactivity excreted in the urine of the nonfistula subjects, nearly $70 \%$ could be extracted following a combination of $\beta$-glucuronidase incubation (48\%) and weak acid $(11 \%)$ and strong acid hydrolyses $(6 \%)$ (Table I). A little over $2 \%$ of the radioactivity could be extracted from the urine before any hydrolytic procedure was performed. The results of hydrolysis and extraction of the urine samples from the biliary fistula patients were similar to those

TABLE II

Excretion of radioactivity in the urine, bile, and stools of women with biliary fistulas injected with $C^{14}$-estriol*

\begin{tabular}{cccccr}
\hline \hline Subject & Age & Urine & Bile & Stools & Total \\
\hline 6 & 44 & 70.0 & 22.2 & 0.0 & 92.2 \\
7 & 36 & 71.3 & 17.3 & 0.2 & 88.8 \\
8 & 54 & 82.9 & 19.6 & 2.2 & 104.7 \\
9 & 68 & 74.2 & 16.2 & 0.0 & 90.4 \\
10 & 67 & 50.4 & 38.5 & 0.0 & 88.9 \\
\hline
\end{tabular}

* Results are shown as percentages of injected dose excreted in 72 hours. 


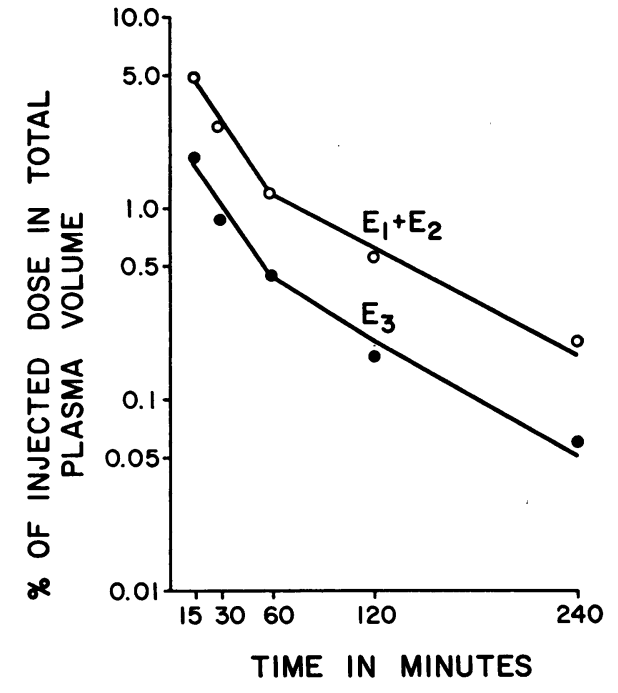

Fig. 1. Clearance from the plasma of the radioACTIVITY FOUND IN THE FREE (UNCONJUGATED) FRACTION FOLLOWING THE INJECTION OF C ${ }^{14}$-LABELED ESTRONE $\left(E_{1}\right)$, ESTRADIOL $\left(E_{2}\right)$, OR ESTRIOL $\left(E_{3}\right)$. Note similarity in the rates of clearance, but lower concentration of radioactivity following estriol injection. In each case only the total radioactivity in the free fractions is represented. In the case of estriol this fraction probably consists predominantly of estriol itself, but in the case of estrone and estradiol, some metabolites of these steroids (estriol and others) may constitute a significant moiety of the free fraction, and the results should be interpreted with these points in mind. Similarily, this statement applies to the glucuronide and sulfate fractions of estrone and estradiol as shown in Figures 2 and 3.

just described. These findings do not differ materially from those observed following the injection of $\mathrm{C}^{14}$-labeled estrone or estradiol. In the bile only about $50 \%$ of the radioactivity present could be extracted following the various hydrolytic procedures, most of the radioactivity being present in the fraction hydrolyzed with strong acid.

A 25-year-old woman in the third trimester of pregnancy was injected with $3 \mu \mathrm{c}$ of $\mathrm{C}^{14}$-estriol and the urine collected for 96 hours. Over $67 \%$ of the injected radioactivity was excreted in the urine within 24 hours and over $83 \%$ during the period of urinary collection. The results of the various hydrolytic procedures were similar to those described for the group of patients in the previous paragraph.

The average excretion of radioactivity in the stools was approximately $2 \%$ after the administration of $\mathrm{C}^{14}$-estriol. This contrasts with the higher fecal radioactivity subsequent to the injection of either $\mathrm{C}^{14}$-estrone or $\mathrm{C}^{14}$-estradiol, which averaged $7 \%$. The difference may be related to the greater amounts of radioactivity excreted via the bile into the gastrointestinal tract in the case of the latter two steroids (18).

The free (unconjugated) radioactivity following $\mathrm{C}^{14}$-estriol administration was cleared from the plasma at an initial rapid rate $\left(t_{\frac{1}{2}} c a .20\right.$ minutes) and at a subsequent slower rate ( $t_{\frac{1}{2}} c a .60$ minutes) (Figure 1). These two rates were very similar to those observed following the injection of $\mathrm{C}^{14}$-labeled estrone or estradiol. The lower levels of radioactivity observed following the injection of $\mathrm{C}^{14}$-estriol may indicate a larger volume of distribution for this steroid or more ready egress of the steroid from the plasma due to lesser protein binding of this steroid as compared to that of estrone and estradiol or both. Within 15 minutes after the injection of $\mathrm{C}^{\mathbf{1 4}}$-estriol, the radioactivity in the plasma "glucuronide fraction" (Figure 2) exceeded that of the "free fraction" (Figure 1) at least fourfold. The activity in the "glucuronide fraction" declined fairly rapidly within the 4-hour period of study. Comparisons

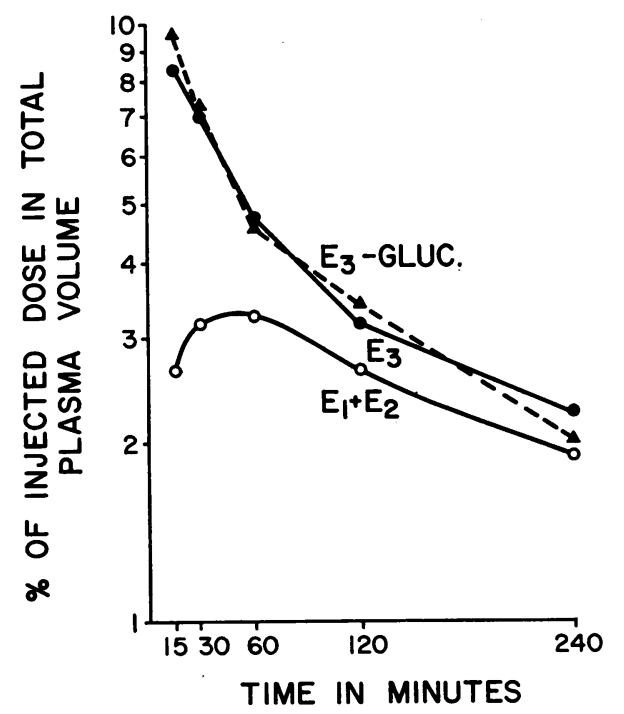

Fig. 2. Disappearance of RAdioactivity FROM THE PLASMA GLUCURONIDE FRACTION AS A FUNCTION OF TIME. The results shown were obtained following the injection of $C^{14}$-labeled estrone $\left(E_{1}\right)$, estradiol $\left(E_{2}\right)$, estriol $\left(E_{3}\right)$, and estriol glucuronide ( $E_{3}$-gluc.). Note that the glucuronides of the last two were cleared at almost identical rates, whereas those of $E_{1}$ and $E_{2}$ showed an initial different rate. 


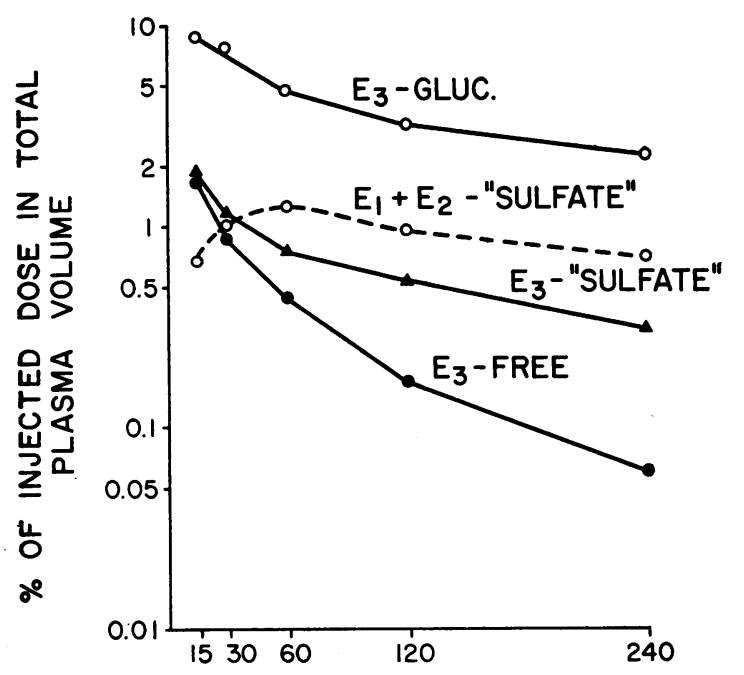

Fig. 3. The clearance from plasma of the free, GLUCURONide, AND SUlfate FRaCtions of INJECTEd $\mathrm{C}^{\mathbf{1 4}}$ ESTRIOL. For comparison, the clearance of the sulfates of $E_{1}$ and $E_{2}$ is shown.

of the radioactivity levels in the plasma following the injection of $\mathrm{C}^{14}$-estrone, estradiol, and estriol are shown in Figures 1 to 3 . The possible reasons for the differences in the curves shown in those figures will be discussed later in the paper.

In Figure 3 are shown the radioactivity levels in the various fractions of the plasma, i.e., free (unconjugated), "sulfate" (radioactivity extractable by solvolysis with ether for 48 hours at $\mathrm{pH}$ 1 ), and the glucuronide moiety, following the injection of $\mathrm{C}^{14}$-estriol. It is interesting to note that the radioactivity in the glucuronide fraction exceeded that in the sulfate fraction by a factor of over 4 at 15 minutes following the injection and by nearly sevenfold at the end of 4 hours. As in the urine, so in the plasma, estriol glucuronide is the predominant conjugate of the estrogen injected. A comparison of the radioactivity in the sulfate plasma fraction following estrone and estradiol injection with that after estriol administration reveals that the former rises for a period of 1 hour, similar to the curve for the plasma glucuronides of estrone and estradiol metabolites, and maintains a level higher than that of the sulfate of estriol. In addition, the ratio of glucuronide to sulfate radioactivity following estrone and estradiol is significantly lower than that observed after estriol injection.

Studies with $C^{14}$-estriol glucuronide. $\mathrm{C}^{14}$-es- triol glucuronide synthesized in our laboratory was injected intravenously into six women, three of whom had biliary fistulas. Over $50 \%$ of the radioactivity appeared in the urine within 4 hours following the injection. The remaining radioactivity appeared in the urine in 48 hours. No radioactivity (Table III) could be detected in the bile of the three subjects with biliary T-tube drainage. Thus, it would appear that the glucuronide of estriol is not excreted in the bile. In the subjects without fistulas, from 60 to about $70 \%$ of the injected radioactivity could be extracted with ether following hydrolysis of the urine with $\beta$-glucuronidase ; $80 \%$ was extractable in the urine of the subjects with biliary fistulas. The amount of radioactivity in the urinary free fraction was negligible and indicates that hydrolysis of the glucuronic acid moiety from the estriol had not occurred to any significant extent in the body.

The clearance of the injected $\mathrm{C}^{14}$-estriol glucuronide from the plasma was almost identical to that shown by the estriol glucuronide fraction present following the injection of $\mathrm{C}^{14}$-estriol (Figure 2). For all practical purposes, no radioactivity could be found in the free fraction from plasma following the administration of the estriol glucuronide, a finding consonant with the lack of radioactivity in the free fraction of the urine. Neither in the urine nor in the plasma was significant radioactivity found following hydrolysis at $\mathrm{pH} 1$ for 48 hours or after exposure to hot strong acid. Interestingly, when an alcoholic extract of the plasma, which contained almost all of the radioactivity in the plasma, was subjected to $\beta$-glucuronidase hydrolysis, over $90 \%$ of the radioactivity became ether extractable. Thus, it would appear that the injected $\mathrm{C}^{14}$-estriol glu-

TABLE III

Excretion of radioactivity in the urine and bile of women injected with $C^{14}$-estriol glucuronide*

\begin{tabular}{cccc}
\hline \hline Subject & Age & Urine & Bile \\
\hline 11 & 52 & 92.0 & \\
12 & 64 & 88.0 & \\
13 & 62 & 86.3 & 0.0 \\
14 & 59 & 78.6 & 0.0 \\
15 & 60 & 80.0 & 0.0 \\
16 & 52 & 91.4 & \\
\hline
\end{tabular}

* Results are shown as percentages of injected dose excreted in 48 hours. 
curonide exists as such in the plasma and is excreted as such in the urine and that no splitting of the conjugate occurs in the body to any significant extent.

The steroid present in the urine following $\mathrm{C}^{14}$ estriol glucuronide injection was shown to be unchanged estriol glucuronide by countercurrent distribution studies, with systems similar to those described later in the paper. In addition, the aglycone was shown to be estriol following incubation with $\beta$-glucuronidase. The estriol was identified by countercurrent distribution and by paper chromatography. In each case the steroid was shown to behave identically with that of standard estriol. No significant radioactivity was found in any other fraction, indicative that the $\mathrm{C}^{14}$-estriol had not been metabolized in the body to any significant degree, if at all.

Association with erythrocytes. The amount of radioactivity associated with the erythrocytes following the injection of $\mathrm{C}^{14}$-estriol did not differ materially from that observed for $\mathrm{C}^{14}$-labeled estrone and estradiol. Thus, 15 minutes following the injection the average amount associated with the total erythrocyte mass in the body was a little less than $2 \%$, at 1 hour about $0.5 \%$, and at 4 hours slightly less than $0.2 \%$ of the injected dose. On the other hand, following the injection of $\mathrm{C}^{14}$-estriol glucuronide the radioactivity associated with the erythrocytes was about threefold that observed following $\mathrm{C}^{14}$-estriol administration (15 minutes, 9\%; 1 hour, 3.3\%; 4 hours, $1.7 \%$ of the injected dose).

Identification of metabolites of injected $C^{14}$ estriol. Levitz and associates (11) had reported the presence of 16-ketoestradiol and 16-epiestriol in the urine of two subjects injected with $\mathrm{C}^{14}$ estriol intramuscularly. The urinary extracts of all the subjects studied were pooled and submitted to countercurrent distributions, as described below, but neither 16-ketoestradiol nor 16epiestriol was found to be present in detectable amounts. To further substantiate our observations a normal female subject, age 32 years, was given $3 \mu \mathrm{c}$ of estriol-16- $\mathrm{C}^{14}$ intravenously. The urine was collected for 48 hours and submitted to the various hydrolytic procedures described previously. In this study the work-up employed countercurrent distribution rather than adsorption chromatography in order to afford a more defini- tive identification and better yields of the metabolites to be studied. In our experience the use of countercurrent distribution has given us more reliable results and better recoveries of the materials studied than afforded by either paper or adsorption chromatography.

Extraction of a major portion of the urine containing $1.8 \times 10^{6} \mathrm{cpm}$ with ether removed a negligible amount of radioactivity. Glucuronides were hydrolyzed by incubation with $300 \mathrm{U}$ per $\mathrm{ml}$ of $\beta$-glucuronidase (Ketodase) at $\mathrm{pH} 5.0$ for 5 days at $37^{\circ} \mathrm{C}$. Continuous extraction with ether at $\mathrm{pH} 5.0$ for 48 hours yielded $918,000 \mathrm{cpm}$. An additional $20 \%$ of the radioactivity was extracted from the urine following mild and strong acid hydrolysis, but only the pooled free and glucuronide extracts were used for the identification of the metabolites.

To the ether extract containing 918,000 cpm was added $10 \mathrm{mg}$ each of estriol, 16-epiestriol, and 16-ketoestradiol. The mixture was subjected to countercurrent distribution $(\mathrm{n}=100)$ in the system $\mathrm{H}_{2} \mathrm{O}: \mathrm{CH}_{3} \mathrm{OH} / \mathrm{CCl}_{4}: \mathrm{CHCl}_{3}, 30: 70 / 50$ : 50 (by volume). Analysis of radioactivity and Kober chromogen showed that the 16-ketoestradiol, epiestriol, and estriol had partition coefficients of $1.0,1.5$, and 4.1 , respectively. The preponderant amount of the radioactivity was associated with the estriol and was not identified further. There was a minor peak with a partition coefficient of 0.63 which had a shoulder that trailed into the 16-ketoestradiol region.

Since the three standards were incompletely separated, tubes 40 to 72 were pooled $(254,000$ $\mathrm{cpm})$, and the residue, after flash evaporation, was treated by the method of Marrian and Bauld (21) for acetonide formation. Countercurrent distribution in the same system showed the three standards to be completely separated with the 16-epiestriol acetonide having a partition coefficient of 0.04 . The major peak of radioactivity was again associated with the estriol standard, and the minor peak was unchanged. The three areas were separately pooled and counted: epiestriol acetonide, $13,000 \mathrm{cpm}$; 16-ketoestradiol, $21,000 \mathrm{cpm}$; estriol, 124,000 cpm.

The 16-epiestriol acetonide was redistributed $(\mathrm{n}=50)$ in the system $n$-hexane $/ \mathrm{CH}_{3} \mathrm{OH}: \mathrm{H}_{2} \mathrm{O}$, $100 / 50: 50$. All of the radioactivity remained in tubes 0 to 3 , leaving the standard $(K=0.9)$ de- 
void of radioactivity (no counts above background).

The 16-ketoestradiol was redistributed $(\mathrm{n}=$ 200 ) in the system $\mathrm{H}_{2} \mathrm{O}: \mathrm{CH}_{3} \mathrm{OH} / \mathrm{CCl}_{4}: \mathrm{CHCl}_{3}$, $30: 70 / 20: 80$. The same pattern prevailed, i.e., the radioactivity peaked $(K=0.20)$ lower than the standard $(\mathrm{K}=0.36)$, but trailed into the 16ketoestradiol area. The radioactivity in this area was now $3,000 \mathrm{cpm}$ and showed no indication of being identical with 16 ketoestradiol.

We concluded, therefore, that although estriol is metabolized to a small extent, it was not converted in the subjects studied according to the scheme proposed by Levitz and associates (11).

\section{Discussion}

Recent studies on estriol metabolism have not only concerned themselves with the metabolic derivation of this steroid, both in pregnant and nonpregnant subjects, but also with its metabolic pathways and fate. To further clarify the latter was the major purpose of this study. Our salient findings are related to the biliary excretion, clearance from plasma, and rate of conjugation of $\mathrm{C}^{14}$-estriol, and the metabolic fate of $\mathrm{C}^{14}$-estriol glucuronide. Each aspect will be discussed separately.

The rate of urinary excretion for the various estrogens is dependent on the amount of the steroid involved in the enterohepatic circulation. Of the three estrogens studied here, estriol appears to be excreted least in the bile. The preponderant part of the estriol (and its possible metabolites) in the bile is reabsorbed via an enterohepatic circulation; about $85 \%$ of the injected estriol is recovered in the urine within 72 hours, with most of that being excreted within the first 24 hours. This contrasts with the urinary excretion of radioactivity following the administration of estrone or estradiol, an excretion characterized by a peak in the second 24 hours and consuming 4 to 6 days for $90 \%$ of the radioactivity to appear in the urine.

These differences in the rates of urinary excretion between estriol on the one hand and estrone and estradiol on the other may be due to at least two factors. One factor is related to the biliary excretion. At least $50 \%$ of the radioactivity is excreted in the bile following the in- jection of estradiol, and the steroid and its metabolites then become involved in an enterohepatic circulation that may trap a considerable portion of the radioactivity for prolonged periods of time.

The different degrees to which the estrogens studied are involved in an enterohepatic circulation are further indicated by the recovery of radioactivity in the stools. Thus, following the injection of $\mathrm{C}^{14}$-estrone or $\mathrm{C}^{14}$-estradiol an average of $7 \%$, and as much as $18 \%$, was recovered in the stools, whereas only $2 \%$ was found when $\mathrm{C}^{14}$ estriol was administered. The repeated recirculation in the enterohepatic system of the former two steroids and their greater excretion in the bile (40 to $60 \%$ ) probably account for the substantial radioactivity found in the stools when estrone or estradiol is administered. In the case of estriol the radioactivity excreted in the bile is rapidly and almost quantitatively reabsorbed, as witnessed by the less than $2 \%$ of radioactivity found in the stools and the relatively rapid excretion in the urine. That a small amount of the estriol may be involved in an enterohepatic circulation is evidenced by the average recovery of $93 \%$ of the radioactivity injected in the biliary fistula subjects and only $87 \%$ in the nonfistula women.

A second factor affecting the rate of urinary excretion of the various estrogens is related to the metabolism of these steroids. The metabolic conversion of estrone and estradiol and subsequent conjugation may consume a substantially longer period of time than that required for the direct conjugation of estriol. A combination of the two factors just discussed may, in fact, be the major factors involved in the delayed urinary excretion of radioactivity following the injection of $\mathrm{C}^{14}$-labeled estrone and estradiol, as compared to estriol.

Examination of Figure 2 reveals a phenomenon that may be related to one of the statements made in the preceding paragraph. The Figure shows that the level of radioactivity in the "glucuronide fraction" of estrone or estradiol rose to a peak at about 60 minutes and then declined at a rate similar to that following the injection of either estriol or estriol glucuronide. It is possible that the rising levels in the glucuronide fraction are due to the time required for conversion of estrone and estradiol to their major metabolite, estriol (1, 
$2)$, a reaction that is slower than conjugation (19).

The decline in radioactivity in the "free fraction" of the plasma following the injection of $\mathrm{C}^{14}$ estriol was characterized by an initial rapid and a subsequent slower rate of clearance; both rates were very similar to those following the injection of estrone or estradiol. As a matter of fact, these rates were not greatly dissimilar from those observed for some other steroids, including nonphenolic ones [deoxycorticosterone (22), progesterone (23), $17 \alpha$-hydroxyprogesterone (24)], and may indicate that removal of steroids from the circulating blood, probably by the liver, is a process whose rate limiting step is similar for a number of steroids. The lower concentration of radioactivity in the plasma following the injection of $\mathrm{C}^{14}$-estriol may be due to a larger volume of distribution in the body, possibly related to the lesser binding of estriol to plasma protein when compared to that of estrone and estradiol (25). That estriol is bound less to human serum albumin (and plasma) has been previously demonstrated in our laboratory (25), and it is possible that this may be responsible for egress of some of the $\mathrm{C}^{14}$-estriol from the blood, resulting in lower concentrations of radioactivity in the plasma. The disparity cannot be ascribed to association with the erythrocytes, since the three estrogens studied were bound to about the same extent by the red blood cells.

Examination of Figure 2 reveals that estriol was rapidly conjugated in the body and initially (15 minutes) reached levels of radioactivity at least threefold those seen following estrone and estradiol administration. The rapidity of conjugation can be judged from the fact that the clearance curve of estriol glucuronide from the plasma following estriol glucuronide administration was almost identical to that when estriol was injected. Although the concentration of radioactivity present as the glucuronide in the plasma was essentially identical following estriol or estriol glucuronide administration, there was a substantially higher amount of estriol glucuronide associated with the erythrocytes than following estriol. This finding may be due to greater water solubility of the estriol glucuronide and ready penetration into the erythrocytes.
The studies with $\mathrm{C}^{14}$-estriol glucuronide revealed several interesting features. Urinary excretion of the conjugated steroid was prompt, and practically none of it was excreted in the bile. This lack of biliary excretion contrasts with the significant $(20 \%)$ excretion of radioactivity in the bile following $\mathrm{C}^{14}$-estriol injection. Thus, these two observations and others point to the fact that the estriol glucuronide was not split significantly in the body. Almost all of the radioactivity in the urine could be recovered following $\beta$-glucuronidase hydrolysis, and the steroid aglycone was shown to be estriol. Ideally, the study should have utilized a doubly labeled estriol conjugate, i.e., one label in the steroid and another on the glucuronide. However, such a doubly labeled compound is not available. These observations plus the fact that no significant radioactivity could be obtained in the "free steroid" fraction of the urine point to the maintenance of the integrity of the estriol glucuronide in the body. This finding is in striking contrast to the behavior of estrone sulfate, which was hydrolyzed extensively when injected into women $(26,27)$.

Our failure to find detectable amounts of radioactive 16-ketoestradiol and 16-epiestriol contrasts with the results described by Levitz and coworkers (11). These differences are difficult to explain. It is possible that the mode of administration they utilized (11), intramuscularly in propylene glycol, may have been an important factor. The intravenous route of administration that we used may have obviated the influence of the intramuscular milieu on the metabolism of estriol. The hydrolytic procedures utilized by Levitz and associates (11) and the recoveries of radioactivity resulting from these procedures (approximately $50 \%$ and $67 \%$ in the two subjects studied, respectively) did not differ substantially from the circumstances and results of our experiments. On the other hand, it is possible that the approaches used for the identification of the metabolites may have contributed to the divergence in the observations. We relied primarily on countercurrent distribution and reverse isotopic dilution, whereas Levitz and associates (11) employed chromatography for separation of steroid mixtures that did contain other radioactive components of nearly identical polar- 
ity. We cannot state whether the other metabolites they mentioned (11) (16-ketoestrone and $16 \alpha$-hydroxyestrone, not rigorously identified by them due to the small quantities available) were present in the urine of the patients of our study, since no effort was made to isolate and identify these compounds. However, the countercurrent distribution results indicate that estriol is changed structurally only to a small extent.

\section{Summary}

The metabolic fate of $\mathrm{C}^{14}$-estriol and $\mathrm{C}^{14}$-estriol glucuronide has been studied following their intravenous injection into women, including subjects with biliary fistulas. The radioactivity following $\mathrm{C}^{14}$-estriol injection is excreted more rapidly in the urine than previously observed when $\mathrm{C}^{14}$-estrone or $\mathrm{C}^{14}$-estradiol was administered. The preponderant part of the radioactivity of the former steroid is excreted in the urine within 24 hours, whereas the peak excretion with the latter two steroids occurs 48 to 72 hours subsequent to injection. In all probability, the involvement of estrone and estradiol in an enterohepatic circulation, owing to the fact that over half of their radioactivity is excreted in the bile, may be the major reason for the differences in the urinary excretory rates. Only $20 \%$ of the $\mathrm{C}^{14}$-estriol was excreted in the bile. $\mathrm{C}^{\mathbf{1 4}}$-estriol was conjugated more rapidly than estrone or estradiol, and only a very small amount of the aglycone was metabolized. By reverse isotopic dilution, 16-ketoestradiol and 16-epiestriol could not be shown to be among the metabolites. $\mathrm{C}^{14}$ estriol glucuronide is rapidly excreted in the urine, and no evidence was obtained that the conjugate had been split to any extent in the body. No biliary excretion of the estriol glucuronide occurred.

\section{Acknowledgments}

We wish to thank Dr. Mortimer Levitz and the American Cancer Society for generous supplies of $16-C^{14}$ estriol. Mrs. Maria Karsay, Mrs. Anne Agacz, and Elek Karsay gave valuable technical assistance. We are particularly grateful to various staff members of the Buffalo General Hospital for allowing us to study their patients with $\mathrm{T}$-tube drainage of bile.

\section{References}

1. Fishman, J., H. L. Bradlow, and T. F. Gallagher. Oxidative metabolism of estrogens. J. Amer. chem. Soc. 1959, 81, 2273.

2. Fishman, J., H. L. Bradlow, and T. F. Gallagher. Oxidative metabolism of estradiol. J. biol. Chem. 1960, 235, 3104.

3. Magendantz, H. G., and K. J. Ryan. Isolation of an estriol precursor, $16 \alpha$-hydroxydehydroepiandrosterone, from umbilical sera. J. clin. Endocr. 1964, 24, 1155.

4. Cassmer, O. Hormone production of the isolated human placenta. Acta endocr. (Kbh.) 1959, suppl. 45.

5. Frandsen, V. A., and G. Stakemann. Urinary excretion of estriol during normal pregnancy. Dan. med. Bull. 1960, 7, 95.

6. Coyle, M. G., M. Greig, and J. Walker. Bloodprogesterone and urinary pregnanediol and œstrogens in fœtal death from severe pre-eclampsia. Lancet 1962, 2, 275.

7. Engel, L. L., B. Baggett, and M. Halla. In vitro metabolism of estradiol-17 $\beta$ by human fetal liver: formation of estriol, 16-epiestriol, estrone and an estriol glucosiduronic acid. Endocrinology 1962, 70, 907.

8. Slaunwhite, W. R., Jr., M. A. Karsay, K. Niswander, and A. A. Sandberg. Hydroxylation of estrone and estradiol by human placenta and fetal liver. Program of the 46th meeting of the Endocrine Society, 1964, 151.

9. Merrill, R. C. Estriol: a review. Physiol. Rev. 1958, 38, 463.

10. Schiller, J., and G. Pincus. The fate of $\alpha$-estradiol and of estriol injected into a human male subject. Arch. Biochem. 1943, 2, 317.

11. Levitz, M., J. R. Spitzer, and G. H. Twombly. Interconversions of 16-oxygenated estrogens. I. The synthesis of estriol-16- $\mathrm{C}^{14}$ and its metabolism in man. J. biol. Chem. 1958, 231, 787.

12. Calvin, H. I., R. L. Vande Wiele, and S. Lieberman. Evidence that steroid sulfates serve as biosynthetic intermediates: in vivo conversion of pregnenolonesulfate- $\mathrm{S}^{35}$ to dehydroisoandrosterone-sulfate- $\mathrm{S}^{35}$. Biochemistry 1963, 2, 648.

13. Calvin, H. I., and S. Lieberman. Evidence that steroid sulfates serve as biosynthetic intermediates. II. In vitro conversion of pregnenolone- ${ }^{8} \mathrm{H}$ sulfate${ }^{85} \mathrm{~S}$ to $17 \alpha$-hydroxypregnenolone- ${ }^{8} \mathrm{H}$ sulfate- $-{ }^{25} \mathrm{~S}$. Biochemistry 1964, 3, 259.

14. Roberts, K. D., L. Bandi, H. I. Calvin, W. D. Drucker, and S. Lieberman. Evidence that cholesterol sulfate is a precursor of steroid hormones. J. Amer. chem. Soc. 1964, 86, 958. 
15. Baulieu, E.-E. Studies of conjugated 17-ketosteroids in a case of adrenal tumor. J. clin. Endocr. 1962, 22, 501.

16. Purdy, R. H., L. L. Engel, and J. L. Oncley. The characterization of estrone sulfate from human plasma. J. biol. Chem. 1961, 236, 1043.

17. Baulieu, E. Studies on androgen metabolism. Recent Progr. Hormone Res. 1965, 21, in press.

18. Sandberg, A. A., and W. R. Slaunwhite, Jr. Studies on phenolic steroids in human subjects. II. The metabolic fate and hepato-biliary-enteric circulation of $\mathrm{C}^{14}$-estrone and $\mathrm{C}^{14}$-estradiol in women. $\mathrm{J}$. clin. Invest. 1957, 36, 1266.

19. Slaunwhite, W. R., Jr., M. A. Lichtman, and A. A. Sandberg. Studies on phenolic steroids in human subjects : VI. Biosynthesis of estriol-glucosiduronic acid-16- ${ }^{14} \mathrm{C}$ by human liver. J. clin. Endocr. 1964, 24, 638.

20. Sandberg, A. A., and W. R. Slaunwhite, Jr. Metabolism of $4-\mathrm{C}^{14}$-testosterone in human subjects. I. Distribution in bile, blood, feces and urine. J. clin. Invest. 1956, 35, 1311.
21. Marrian, G. F., and W. S. Bauld. The isolation of 16-epiOestriol from the urine of pregnant women. Biochem. J. 1955, 59, 136.

22. Sandberg, A. A., W. R. Slaunwhite, Jr., and E. Chang. Metabolism of $\mathrm{C}^{14}$-deoxycorticosterone in human subjects. In preparation.

23. Sandberg, A. A., and W. R. Slaunwhite, Jr. The metabolic fate of $\mathrm{C}^{\mathbf{1 4}}$-progesterone in human subjects. J. clin. Endocr. 1958, 18, 253.

24. Slaunwhite, W. R., Jr., and A. A. Sandberg. Disposition of radioactive $17 \alpha$-hydroxyprogesterone, $6 \alpha$-methyl-17 $\alpha$-acetoxyprogesterone and $6 \alpha$-methylprednisolone in human subjects. J. clin. Endocr. 1961, 21, 753.

25. Slaunwhite, W. R., Jr., H. Rosenthal, and A. A. Sandberg. Interactions of steroids with human plasma proteins. Arch. Biochem. 1963, 100, 486.

26. Twombly, G. H., and M. Levitz. Metabolism of estrone- $\mathrm{C}^{14}-16$ sulfate in women. Amer. J. Obstet. Gynec. 1960, 80, 889.

27. Sandberg, A. A., and W. R. Slaunwhite, Jr. Unpublished results. 